\title{
The Practice and Value Reconstruction of Modern Information Ecological Ethics: Beliefs, Argument and Strategy ${ }^{+}$
}

\author{
Yuan Zushe \\ Institute of Philosophy and Government Management, Shaanxi Normal University, Xi'an 710119, China; \\ zushe@163.com; Tel.: +86-135-0918-9175 \\ + Presented at the IS4SI 2017 Summit DIGITALISATION FOR A SUSTAINABLE SOCIETY, Gothenburg, \\ Sweden, 12-16 June 2017.
}

Published: 8 June 2017

\begin{abstract}
As a kind of thinking mechanism that grasps motion, change and development of objects on the whole, systematic thinking contains a whole set of thinking principles, methods and operation procedures. With the uprising popularity of studies on informational system science and complexity theory, information reveals a new field that the philosophy of the past has not discovered. Wu's works are putting forward a wholly new scientific thinking way: the Informational Thinking. We can conclude rationally from Wu's explanations of information that the character of informational thinking way can include and surpass the basic idea of systematic thinking way. So far as the whole process of scientific cognition is concerned, functions of informational thinking are expanded in several aspects. Information civilization is undoubtedly the latest pattern of contemporary human civilization. Nowadays, people are hard to escape the fate of survival of informatization. Its theory and practice are fundamentally reforming and impressively reconstructing existence style of modern society, as well as the modern individual life belief, emotion, behavior, attitude and psychology in every respect. The reconstruction of modern information ecological ethics must face to face with the openness of information culture, noncontrollability, freedom, permeability, internationalism, technicality, virtuality, popularity, diversity and immediacy due to the rapid development of information technology and deal with the severe challenges to social management as a result of the tendency of the disordering of network culture, non-controllability, anarchy and liberalization 7. Taking Control of the Optimal Systematic Condition of Objects as the Aim. The modern sense of information ecology refers to a system which is combined by man, practice, value and technology existing in a specific regional environment, which plays a role of educated existence in the integrated system. With the continuing expansion and penetrating of informatization, the spiritual and cultural life of modern society is confronted with the severe challenges of complanation, homogeneity, non-privacy or even alienation and so on. At the same time, it leads to a series of social ethical issues, such as infringement of intellectual property rights, illegal access to information, the illegal use of information technology, information attribution of liability, authorization, infringement of personal right of privacy, infringement of image rights, etc. The emergence of these problems is rooted in information ecological imbalance (It refers to the disequilibrium state among information, human and environment), that is to say, there are information exchange blocks between the internal and external ecological system or imbalance between its elements and subsystems. Information ecological imbalance mainly reflects in the following five aspects: excessive information, information monopoly, information infringing, information pollution and the information syndrome. The root cause of ecological imbalance lies in its entropy. In this increasingly informationized and intelligentized era, "the means of technology" in the sense of pure knowledge is undoubtedly important and indispensable with regard to alleviating the encroachment on information subjects brought by excessive and detrimental information substantially. However, in terms of modern sociology of knowledge, it is more important to pay a close attention to the autonomous construction and normative function of the
\end{abstract}


culture, values and ethics beyond pure knowledge, to keep in mind "the balance of information ecology", the core value subject of information practice and information culture, to abide by the law of information production, information transmission, information consumption and information disintegration with an aim to ensure the reasonable match of the categories and numbers of information subjects, the coordination of the factors of information ecological environment, the adjustment of information subjects and information ecological environment and the efficient circulation of the whole information system. Thus, the premium practice-value reconstruction of modern information ecological ethics must be based on the diversity and differentiation of information ecology and the principle of coordination, mutual benefits and symbiosis with the aspiration of promoting the coordinated development between human society and information environment. The reconstruction should strive to create a harmonious and open environment to produce information and share information in a fair and just way, to configure and foster more sharing information resources reasonably, to realize the balance of information ecological system and ultimately to promote the sustainable and healthy development of humans, information environment and even the material and spiritual life of human society.

Keywords: systematic thinking; theoretical construction; functional scope

(C) 2017 by the author. Licensee MDPI, Basel, Switzerland. This article is an open access article distributed under the terms and conditions of the Creative Commons Attribution (CC BY) license (http://creativecommons.org/licenses/by/4.0/). 